\title{
Embracing Multilingualism Across Educational Contexts. Edited by Corinne A. Seals and Vincent Ieni Olsen-Reeder. Wellington, Victoria University Press, 2019. 389 pp. ISBN 9781776562916
}

\author{
Antonina A. Kharkovskaya \\ Samara State University
}

Correspondence concerning this article should be addressed to Antonina A. Kharkovskaya, 34, Moskovskoye shosse, Samara, 443086, Russian Federation. E-mail: aax2009@mail.ru

The book entitled "Embracing Multilingualism Across Educational Contexts" edited by Corinne A. Seals and Vincent Ieni Olsen-Reeder, Victoria University Press was first published in 2019. It is aimed at revealing and systematizing current cultural trends and experiences embodied in both nationally identical and internationally oriented projects within the educational space of the 21st century. The book is also aimed at mobilizing the education policymakers, the international community, and civil society organizations trying to ensure that the right to education for all people - particularly language and cultural minorities - is upheld both in developing and developed countries.

The authors of the book share their views on some urgent and far-reaching issues related to rapid changes in modern world educational paradigms caused by dynamically developing interrelationships between global communication and national development on one hand and requirements to correlate emerging virtual forms of collaboration in different spheres of human activities on the international level on the other.

The significance of this monograph is the emphasis on "translanguaging", which is usually interpreted as a rapidly growing field of research both in theory and in practice because it provides an opportunity to push forward adequate understanding of renewed linguistic terminology and is able to challenge cross-cultural experiences and multimodal means of expression and communication that multilinguals navigate in educational settings on a daily basis. Touching on traditional and diverse elements of multilingual research, such as code switching, code meshing, polylingualism, polylanguaging, plurilingualism, hybridity, hybrid language practices, and flexible dynamic bilingual education, the contributors focus strongly upon the ability of translanguaging to assist in explaining how multilinguals go about their language choices in real contexts. The book also takes a fresh look at the necessity to transform various teaching/ learning methods and empirical educational schemes to meet the challenges of the second millennium. 
The use of translanguaging educational potential for revealing effective ways and means of social and cultural adaptation to modern changes in language training models for multilinguals in the epoch of globalization. Modern experts in education postulate the thesis that the need to facilitate the process of language acquisition in different multinational communities is a 'must' for both Western countries (Sweden, Germany, Austria, etc.) facing the problems of migration consequences and for Eastern countries with an original multilingual schoolscape, where the necessity to meet the challenges of globalization is considered a strong impetus for introducing innovative shifts into the language educational paradigms with regard to both national and international educational settings. The book also makes an interesting point about translanguaging methodology integrated into the curricula and syllabi for multilingual audiences.

The book is divided into 13 chapters, progressing from a focus on translanguaging ways of understanding multilinguals' interactions with the world toward building awareness of the cognitive, emotional, and social merits of multilingualism and multilingual education in the terms of ethnographic approach, interview methodology, and translingual pedagogical models. The essays, written by authors who are without any doubt experts in the study of translanguaging ways and means aimed at effective modifying modern methods of language training, are devoted to the detailed descriptions of cases with regard to ethnographic, sociolinguistic, cognitive, and pedagogical aspects of professional educational experiences. The contributions are grouped into two parts. The key topics covered by the authors of the essays from the first strand of the book concern the advantages of encouraging linguistic diversity and multilingualism in educational contexts when minority languages (Samoan, the language versions of Māori communities in New Zealand, the Ryukyuan language family consisting of at least five distinct languages -Amamian, Kunigami, Uchinaaguchi/Okinawan, Miyakoan, Yaeyaman, Dunan, traditionally spoken in the Ryukyu Islands - a chain of islands in the southwest region of Japan ) are involved in classroom language training across a wide range of current linguistic environments. Each chapter included in the book contains a description of both teachers' and students' achievements and outcomes due to the application of various ways and means aimed at increasing the process of adaptation to new linguocultural settings. The merits of teaching techniques based on the application of a home or mother language in the classrooms with a number of different national communities worldwide to provide a passionate intellectual engagement with the challenges to support second language acquisition in education are discussed by some of the most distinguished experts in bilingual training (Corinne A. Seals and Russell Pine from Victoria University of Wellington; Verbra Pfeiffer from Stellenbosch University in South Africa, majoring in multilingual education; Chun-Mei Chen from Taiwan and Judith Purkarthofer from the Center of Minority Languages in Oslo University working out the most effective dominant language regimes in the bilingual communities). The most effective models for the socialization of children through the appropriate language choice, which helps to keep the reality of their homes and the knowledge of wider community traditions, are described in details in Chapter 2 "Using both Samoan and English to shape understanding, reasoning, and appreciation during a book experience in an A'oga Amata: An example of translanguaging” prepared by Feaua ' $i$ Amosa Burgess and Sadie Fiti and in Chaper 4 entitled "TransAcquisition Pedagogy with emergent bilinguals in Indigenous and minority groups for cultural and linguistic sustainability" written by Sophie Tauwehe Tamati. Both authors are summing up the outcomes of their collaboration with a teaching staff conducting experiments on mixed groups of students. The discussion of the merits and demerits of translanguage pedagogical techniques contributing to a holistic approach to language education with varied heritage language backgrounds proves the advantages of introducing home language elements in oral communication and in classroom activities. One noticeable feature about the cases is the less frequent use of dual language interactions between the teacher and the children who feel free to use their home language vocabulary while talking with their friends and classmates.

The language scholars' opinion about code-switching in these cases is tolerant enough. They believe that a dedicated focus on heritage languages contributes to both Indigenous and immigrant education level due to the necessity of their continued revitalization and maintenance in a time when linguistic diversity is constantly under threat by languages perceived as more powerful. However, the crucial role of the first language in the students' linguistic repertoire is strongly emphasized by the researchers recommending the integration of home language elements into the teaching instructions and classroom activities than eliminating them from the school curricula. Analyzing the linguistic repertoires of the students with varied heritage language backgrounds in terms of translanguage pedagogical techniques, some authors appreciate the use of alternative languages for shaping understanding and reasoning skills (Judith Purkarthofer, Jenny Rosŭn, Boglбrka Straszer, and Esa Wedin). They believe it is only within the translanguaging approach that an appropriate educational model can be created. 
Another disputable issue concerns the learners' age. It is in many cases that the translanguaging pedagogical profile is traditionally aimed at forming conversational skills relevant for young learners who live with their families and have to use home languages both at home and in schools. Chapter 3 "The use of translanguaging to bridge sociocultural knowledge in a puna reo" presents the results of research conducted in 2017. The authors discuss the educational profile of the second most-spoken language in New Zealand, which is a superdiverse country with over 160 languages spoken by residents every day. Te reo Māori is recognized as an integral part of the country's multilingual and multicultural heritage, and has been Aotearoa NZ's first officially recognized language (since 1987) and, therefore, is justly considered the language of Māori identity. Taking into consideration the necessity to promote the preservation and revitalization of Te reo Māori's linguistic and cultural identity, the local government is sponsoring teaching environments for te reo Māori providing the puna reo project, within which children under five years old are taught bilingually through te reo Māori and English. The puna reo is a place where multicultural, multilingual and Aotearoa NZ is fostered, as well as being a place where translanguaging naturally occurs.

As a concluding statement to this part of the book, it's possible to say that the discussions around developments in minority languages teaching projects and language acquisition aimed at using translanguaging to bridge sociocultural knowledge and national identity, because it is based upon a good mix of academic experience, global knowledge, and contemporary research accounts.

In the second part of the book, the authors interpreting translanguaging potential present a comprehensive and well-balanced narrative of the strategies integrated into the educational spaces of European countries. They focus their attention on the problems of migrants' needs in foreign language contexts and the requirements of modern educational language standards through which the process of foreign high school students' adaptation is facilitated on the international level. One peculiar feature of these issues is the shift from oral communication towards writing, which is considered a self-regulating mechanism in which bi/multilingual students can engage, rather than a pedagogy to be used in the teaching of writing itself. The students' awareness of their home language and the ways they can use it to strengthen their academic writing skills are discussed in detail in Chapter 7 "Austria's curriculum for heritage language education across languages: A case study in balancing speakers' needs on the local, national and international level". Here, Judith Purkarthofe dwells on the Austrian case of code-switching, distinguishing between two main strands of research. The first strand, named the linguistic proficiency approach, takes a stronger interest in an individual's proficiency and focuses on pedagogical aspects of supporting language learners when they are neither native speakers nor foreign language learners (Turkish immigrants in the Netherlands talking about their feelings of anxiety in relation to their heritage language). The second strand, that the authors rename the self-esteem approach, focuses on the social conditions of learning: social hierarchies and inequalities both within and beyond the classroom, various geopolitical factors, etc.). Furthermore, in this chapter the author also writes about specific ways and means for promoting teachers' language education in Austria, because the linguistic and pedagogical qualifications of teachers are not thought of as a 'must' in this country. However, the situation with the requirements for teaching staff's competence has changed and later some reforms in education development curriculum for teachers were introduced.

Chapter 8, "Maintaining, developing and revitalizing: Language ideologies in national education policy and home language instruction in compulsory school in Sweden", and Chapter 9, "Embracing multilingualism in school through multilingual' educational staff: Insights into the interplay of policies and practices", deal with Swedish and German 'multilingual change', which may be regarded as an integrative model aimed at integrating newly arrived pupils and their language practices in mainstream classes from the very beginning and constructing multilingual teaching teams at a starting school level.

In Chapter 9, the scholars show the importance of psycholinguistic and socio-political factors for regarding expansion of linguistic resources aimed at balancing migration-related resources in Germany is growing, due to the emergence of multilingualism resulting from transnational mobility. At the same time, the opposition to this multilingual reality and the monolingual approach in the educational contexts of many countries, including Germany, is demonstrated. This discrepancy calls for new trends within the multilingual educational models and consequently it requires the involvement of both theoreticians and practitioners in the process of modelling creation. The learners' language biographies together with sociolects, regiolects, and different linguistic registers of national languages are also taken into consideration by language policymakers. Assuming that social power relations are certainly dependent upon different forms of capital: cultural capital, social 
capital, and economic capital, the authors believe that the position of an individual within the social space is determined by the capital it holds, i.e. by competencies and educational qualifications, by social contacts, and by material possessions. Commenting on different market values of languages and their varieties within a society, the authors conclude that a certain way of speaking always subliminally refers to the origin of the individual, his or her educational career, and his or her position in the social space. Thus, speakers of dialects or minority languages are unconsciously socially classified and are often ascribed a low level of professional competence. The socially legitimate majority language, on the other hand, functions as cultural capital that can be transformed into economic capital. These hierarchical differences between languages are not natural, however, but socio-politically constructed. After Bourdieu's (1990) theory of language as capital and linguistic market, the authors state that language practices might be regarded as strategies of self-positioning in social spaces, which is a convincing argument for the improvement of existing educational programs for adaptation and integration. Chapter 9 "Experiences of attitudes to translanguaging in the classroom" (Vesna Busic and Kirk P. H. Sullivan) presents an overview of Swedish education policies, specifically in relation to the political and social ideas that have created the current conflicting discourses in law and policy. Focusing on the legal aspects of protecting the status of Swedish from English, both experts stress the points related to creating not only a linguistic hierarchy with Swedish at the top, but also conflict situations that are occurring due to educational policies promoting multilingualism. Developing theoretical assumptions about translanguaging as an effective educational approach in which teachers and students are allowed to use all their linguistic and semiotic resources in teaching and learning, the scholars write about the advantages of integrated applications of linguistic and semiotic resources in language education.

To develop the translanguaging ideology in Chapters $\mathbf{1 0}$ and $\mathbf{1 1}$ entitled "New to the classroom: Experiences of attitudes to translanguaging" and "Remixing pedagogies and fluidity of spaces in a community-based schoolscape", the thesis of translanguaging's contribution into modern teaching and learning methodology based on the integration of multilingual experiences is supported by visual aids and by speculations about the merits of various pedagogical cases intended to navigate learners in their multilingual everyday life and existence.
"Multilingual education: Encouraging students to use their language backgrounds" written by Verbra Pfeiffer, provides a detailed account of the attempts to find appropriate ways to use a home language when writing for academic purposes. The differences in educational university standards for academic writing in South Africa and in Switzerland, multilinguals in those countries have to deal with similar challenges when they write in one language and think in another. Taking up the issue of home language integration in the university curriculum, Pfeiffer proves the advantages of the educational approach based on translanguaging within which the home language's role is relevant for both teachers' and learners' academic performance in different geopolitical situations.

The final chapter, "Implementation of a Bilingual Model Based on the Integration of Translanguaging, English, and Content", and the Conclusion under the title "Reflecting on Trends in Translanguaging across Educational Contexts" are devoted to summing up the most popular trends in modern bilingual and multilingual educational spaces and the role of diverse language policy in establishing various schemes providing immersive language education on a global scale.

There is one passage in the book under review that stands apart from the rest of the issues and it concerns the ideas of political discourse associated with the diversity of modern educational spaces caused by the expansion of cultural, economic, and linguistic mobility and by the necessity of uniting efforts in the struggle for national identification integrated into international educational projects. On this issue, the author evaluates the merits of a multilingualism educational approach to the development of innovative strategies aimed at balancing the most interesting empirical results obtained by the contributors.

Postulating the ideas of multicultural cooperation for the language educational profile, the contributors are using the term 'translanguaging', which seems disputable in some cases and might be replaced by another more acceptable terminological unit 'code-switching'. It could also be useful to add some ideas and concepts revealing the details of language interactions occurring in the professional discourses embracing various training schemes from the university educational settings. 


\section{ANTONINA A. KHARKOVSKAYA}

A wide range of information about translanguaging as a means of innovating the multilingual educational space covered in this book underlines the validity of the outcomes and the flexibility of the strategies described by the experts in multilingual educational environments. The well-structured and carefully prepared bibliographies serve as useful navigators in the voluminous cross-cultural research space.

Overall, "Embracing Multilingualism Across Educational Contexts" is a comprehensive and significant contribution to a better understanding of theory and practice on multilingual education in the context of globalization. 